\title{
ELECTROLYTIC REDUCTION OF INDIGO IN PYRIDINE APPLICATION TO THE DETERMINATION OF DISSOLVED OXYGEN
}

\author{
D. A. Hall* and P.J. Elving \\ The University of Michigan, Ann Arbor, Michigan
}

\begin{abstract}
The electrochemical reduction of indigo in pyridine as solvent has been investigated in connection with the determination of oxygen dissolved in pyridine, using polarography, cyclic voltammetry, controlled electrode potential electrolysis and coulometry. In the absence of protons, the total current of the first and second reduction waves for an unsaturated solution of indigo $\left(\mathrm{LiClO}_{4}\right.$ as background electrolyte) apparently represents a one-electron transfer. In the presence of an excess of available protons (added as pyridinium nitrate), indigo is reduced in a reversible two-electron process to indigo white (leucoindigo). The rapid conversion of indigo white to indigo by oxygen in pyridine solution can be used to determine coulometrically the concentration of oxygen in pyridine via measurement of the indigo produced on adding the pyridine-oxygen sample to a solution of in situ electrolytically generated indigo white. The latter approach indicated a general method for the determination of dissolved oxygen in nonaqueous solvents.
\end{abstract}

\section{Introduction}

Indigo (formula shown in Eq. (I) below) forms a macroscopically reversible redox system in aqueous solution, e.g., it can be reduced in alkaline solution by hydrosulfite to leucoindigo or indigo white, which may then be oxidized back to the original indigo by oxygen. The reaction involved is generally accepted [1] to be a two-electron (2e) reduction with the isolated indigo white having two more hydrogen atoms than indigo.

Since indigo white is so readily air-oxidized in aqueous alkaline solution to indigo, the possibility was considered that it would undergo the same reaction in pyridine, thus providing the basis of a method for the electrochemical determination of dissolved oxygen in pyridine, in which the authors were interested in connection with the investigation by polarographic technics of phenomena in pyridine as solvent. This possibility was strengthened by the fact that Gupta [2] established potentiometrically the oxidation-reduction potential of indigo (saturated solution in pyridine) in

- Present address: Eli Lilly Co., Indianapolis, Indiana.

Received: September 23, 1970 
the presence of an excess of protons ( $\mathrm{HCl}$ gas bubbled into the pyridine until it was $0.2 \mathrm{M}$ in $\mathrm{HCl}$ ) as $-0.220 \mathrm{~V}$ vs a $0.046 \mathrm{NAg}(\mathrm{I}) / \mathrm{Ag}$ electrode in pyridine. Consequently, the polarography of indigo at the dropping mercury electrode (D. M. E.) and its electrolytic reduction at a mercury pool in pyridine was investigated, as well as the feasibility of using the indigo-indigo white redox system for the determination of dissolved oxygen in pyridine by means of coulometry. It is readily apparent that this approach could provide a general method for the determination of dissolved oxygen in nonaqueous media.

Detailed study of the redox behavior of indigo in aqueous solution by electrochemical methods has been hampered by its insolubility. The indigo mono-, di- and trisulfonates, however, are water-soluble.

Polarographically, the disulfonate exhibits an anomalous wave $[3,4]$, which has been ascribed to adsorption [5]; the half-wave potential, $E_{1 / 2}$. for the main wave becomes slightly more negative with increasing concentration at $\mathrm{pH} 2.6[6]$; stable waves were obtained between $\mathrm{pH} 1.5$ and 11 (pH varied by $\mathrm{HCl}+\mathrm{NaOH}$ ) [6].

It should be noted that more conventional methods for determining oxygen in pyridine do not yield satisfactory results. Direct polarographic measurement of oxygen in pyridine - as is not infrequently the case for the electrochemical behavior of oxygen in organic solvents - does not always yield unambiguous results due to the complexity of oxygen reduction in such media, e.g., formation of superoxide as well as peroxide species and of electrode films. Determination of oxygen by variants of the Winkler procedure gives nonreproducible results. Furthermore, the low oxygen levels offer additional problems in terms of sensitivity and reproducibility, e.g., a $0.13 \mathrm{mM}$ oxygen solution is equivalent to $4 \mathrm{mg}$ per liter.

\section{Experimental}

\section{Chemicals}

Chemicals were purified or otherwise treated, as follows: Pyridine (J. T. Baker), twice fractionally crystallized [7]; indigo (National Aniline), dried for $2 \mathrm{hr}$ at $110^{\circ} \mathrm{C}$; tetraethylammonium perchlorate (Fastman), vacuum dried; lithium perchlorate (G. Frederick Smith), dried for $2 \mathrm{hr}$ at $110^{\circ} \mathrm{C}$; argon (Matheson Company; used for purging solutions), passed through anhydrous calcium sulfate and then saturated with pyridine; pyridinium nitrate, recrystallized from acetone.

\section{Apparatus}

A water-jacketed three-compartment electrolytic cell was used for both polarography and coulometry. Sintered medium porosity glass disks and gel salt bridges separated the compartments; the bridges were $0.1 \mathrm{M}$ (Et) $)_{4} \mathrm{NClO}_{4}$ in pyridine plus $7.5 \%$ by weight of methyl cellulose or $0.8 \mathrm{M}$ $\mathrm{LiClO}_{4}$ in pyridine plus $10 \%$ by weight of methyl cellulose, depending on the background electrolyte used. One end compartment contained a 
platinum gauze counter electrode; the other contained a normal silver reference electrode in pyridine (NAgE) [8]. The center compartment contained the test solution under examination with a D. M. E. capillary for polarography or a mercury pool electrode for cyclic voltammetry and coulometry. The D. M. E. capillary, made from marine barometer tubing, had an m $\mathrm{m}^{2 / 3} \mathrm{t}^{1 / 6}$ product of 1.56 in $0.1 \mathrm{M} \mathrm{LiClO}$ in pyridine at open circuit. The mercury pool working electrode used for coulometry was $5.7 \mathrm{~cm}^{2}$ in area and was stirred by a magnetically rotated polyethylenecoated stirring bar.

Polarograms were recorded on a Sargent Model XV polarograph in conjunction with a Sargent Model "A" IR compensator. Coulometry at controlled electrode potential was done with a previously described [9] operational amplifier unit, which was capable of a 5-ma. output at $100 \mathrm{~V}$, in conjunction with a variable potential battery source and an integrator unit comprised of a Dymec Model Dy-2210 voltage-to-frequency converter and a Hewlett-Packard Model 521-AR decade counter. The potential of the mercury pool vs NAgE was continuously monitored with a Sargent student-type potentiometer.

Spectra were taken with a Beckman Model DB spectrophotometer and $1-\mathrm{cm}$ quartz cells.

\section{Polarographic Procedure}

Stock solutions of chemicals in pyridine were prepared by accepted procedures, except that indigo and pyridinium nitrate were added as solids. Test solutions were prepared of the compositions indicated, were purged of oxygen by an argon stream, and were examined in the usual manner.

All potentials given are vs. NAgE, whose potential vs the aqueous saturated calomel electrode is $0.09 \mathrm{~V}$. [8].

\section{Coulometric Procedure}

A measured volume of pyridine $\left(0.1 \mathrm{M}\right.$ in $(\mathrm{Et})_{4}$ or $\left.\mathrm{LiClCo}_{4}\right)$ was added to the cell, followed by sufficient pyridinium nitrate to give a concentration of 0.00 to $50.0 \mathrm{mM}$. All three cell compartments, except where otherwise noted, were purged with argon for $30 \mathrm{~min}$ to remove dissolved oxygen. The system, with argon still flowing into the solution, was then electrolyzed at a potential $0.3 \mathrm{~V}$ more negative than the indigo electrolysis potential to be used, until a steady background current was reached, which in all cases was less than $25 \mu \mathrm{A}$. for the stirring rate used. The argon flow in the working electrode compartment was stopped and a known amount of indigo added. The solution was again purged for $30 \mathrm{~min}$; a polarogram was taken, and, with the argon flowing through the solution, the indigo was reduced at the potential of interest on the limiting current plateau until the current returned to the previous background magnitude, except where otherwise noted; a polarogram was then taken of the reduced indigo solution.

To test the repeatibility of the results obtained, the cell was opened to the air for at least $15 \mathrm{~min}$ to allow the reduced indigo to be reoxidized, 
the solution was then deaerated for $30 \mathrm{~min}$, a polarogram taken to assure that reoxidation was complete, and the indigo was again reduced coulometrically.

\section{Determination of Dissolved Oxygen: Procedure}

A $0.5 \mathrm{mM}$ indigo solution in pyridine $\left(0.1 \mathrm{M}\right.$ in $\mathrm{LiClO}_{4}$ and $50 \mathrm{mM}$ in pyridinium nitrate) is coulometrically reduced at $-0.38 \mathrm{~V}$ to indigo white as previously described. The argon bubbler is then removed from the solution, but argon is allowed to flow over the solution surface. A known volume of sample, e.g., air-saturated pyridine, is then introduced by pipet below the surface of the indigo white solution. After $5 \mathrm{~min}$, the argon bubbler is lowered into the solution and the indigo formed is coulometrically electrolyzed at $-0.38 \mathrm{~V}$. The ratio of the quantity of electricity, i.e., number of coulombs or instrument counts, passed per sample to that passed for the initial indigo reduction, when multiplied by the number of milliequivalents of indigo determined coulometrically in the initial reduction, assuming that the faradaic $n$ equals 2 , gives the number of milliequivalents of oxygen reacted; the latter number is multiplied by 1.22 to correct for the loss of indigo as subsequently discussed. On the basis of a $2 \mathrm{e}$ transfer per oxygen atom, the amount and concentration of oxygen can then be calculated.

\section{Results}

\section{Polarographic Behavior of Indigo}

\section{Lithium Perchlorate Background}

Indigo is only slightly soluble in pyridine; its saturation concentration in $0.1 \mathrm{M} \mathrm{LiClO}$ solution is estimated to be about $0.14 \mathrm{mM}$, based on geometric analysis of the curves obtained in exhaustive electrolysis for current flow vs total current passed, e.g., curves analogous to those of Fig. 4, and $0.13 \mathrm{mM}$ based on polarography of a saturated solution in the presence of protons, as subsequently described.

In acid-free $0.1 \mathrm{M} \mathrm{LiClO}$ solution, indigo gives three polarographic waves in freshly prepared unsaturated solution and two waves in freshly saturated solution, containing excess solid indigo (Table I). An aged $0.11 \mathrm{mM}$ solution and a treated $0.2 \mathrm{mM}$ solution each gave four waves, the potentials for the first three of which were comparable to those for the fresh undersaturated solutions. In freshly prepared solutions containing undissolved indigo, i.e., greater than $0.2 \mathrm{mM}$, the polarographic pattern seems to stabilize to two waves at $-0.60 \pm 0.01 \mathrm{~V}$ and $-0.89 \pm 0.01 \mathrm{~V}$.

Protons in the form of available acid in pyridine were added as pyridinium nitrate (pyrH $\mathrm{NO}_{3}$ ). The variation of the limiting current with increasing [pyrHNO $\mathrm{H}_{3}$ ]/[indigo] ratio for a $0.11 \mathrm{mM}$ indigo solution is shown 
TABLE I. Polarographic behavior of indigo in pyridine.

\begin{tabular}{|c|c|c|c|c|c|c|c|c|c|c|}
\hline \multirow{2}{*}{$\begin{array}{c}\begin{array}{c}\text { Indigo } \\
\text { Concn. }\end{array} \\
\mathrm{mM} \\
\end{array}$} & \multirow{2}{*}{$\begin{array}{c}\mathrm{HPyrNO}_{3} \\
\text { Conen. } \\
\mathrm{mM}\end{array}$} & \multicolumn{3}{|c|}{ Wave I } & \multicolumn{3}{|c|}{ Wave II } & \multicolumn{3}{|c|}{ Wave III } \\
\hline & & $\begin{array}{c}-E_{1 / 2} \\
V\end{array}$ & $\begin{array}{l}\dot{i}_{1} \\
\mu \mathrm{A}\end{array}$ & $\begin{array}{l}\text { Slope } \\
\mathrm{mV}\end{array}$ & $\begin{array}{c}-E_{1} / 2 \\
V\end{array}$ & $\begin{array}{l}1_{1} \\
\mu A \\
\end{array}$ & $\begin{array}{c}\text { Slope } \\
\mathrm{mV}\end{array}$ & $\begin{array}{c}E_{1} / 2 \\
V\end{array}$ & $\begin{array}{l}i_{1} \\
\mu \mathrm{A}\end{array}$ & $\begin{array}{l}\text { Slope } \\
\mathrm{mV}\end{array}$ \\
\hline \multicolumn{11}{|c|}{$0.1 \mathrm{M} \mathrm{LiClO}_{4}$ Solution } \\
\hline$<$ sat'n.d & 0 & 0.47 & 0.11 & 40 & 0.62 & 0.08 & 40 & 0.78 & 0.09 & 70 \\
\hline 0.11 & 0 & 0.44 & 0.13 & 43 & 0.60 & 0.18 & 44 & 0.83 & 0.13 & 75 \\
\hline \multirow[t]{2}{*}{$0.11^{b}$} & 0 & 0.50 & 0.16 & 48 & 0.70 & 0.15 & 80 & 0.82 & 0.17 & 48 \\
\hline & & & & & & & & IV 1.12 & 0.13 & 72 \\
\hline \multirow[t]{2}{*}{$0.20^{\mathrm{C}}$} & 0 & 0.46 & 0.13 & 38 & 0.60 & 0.44 & 70 & 0.88 & 0.30 & 60 \\
\hline & & & & & & & & IV 1.08 & 0.10 & 42 \\
\hline 0.50 & o & 0.60 & 0.26 & 54 & 0.89 & 0.40 & 87 & & & \\
\hline 0.50 & 0 & 0.60 & 0.33 & 82 & 0.88 & 0.42 & 100 & & & \\
\hline 2.00 & 0 & 0.60 & 0.39 & 68 & 0.90 & 0.60 & 84 & & & \\
\hline 2.00 & o & 0.61 & 0.38 & 64 & 0.89 & 1.08 & 82 & & & \\
\hline 0.50 & 1 & 0.39 & 0.69 & 40 & & & & & & \\
\hline 0.50 & 2 & 0.37 & 0.72 & 79 & & & & & & \\
\hline 0.50 & 10 & 0.31 & 0.64 & 30 & & & & & & \\
\hline 0.50 & 50 & 0.26 & 0.68 & 35 & \multicolumn{2}{|c|}{$(0.620 .10)^{\mathrm{e}}$} & & & & \\
\hline \multicolumn{11}{|c|}{$0.1 \mathrm{M} \mathrm{Et}_{4} \mathrm{NClO}_{4}$ Solution } \\
\hline 0.40 & 0 & 0.82 & 0.84 & 63 & 1.22 & 0.68 & 114 & & & \\
\hline 2.00 & 0 & 0.83 & 0.42 & 52 & 1.28 & 1.03 & 140 & & & \\
\hline 2.00 & 0 & 0.83 & 0.36 & 54 & 1.25 & 0.58 & 78 & & & \\
\hline 5.00 & 0 & 0.84 & 0.36 & 50 & 1.24 & 0.42 & 60 & & & \\
\hline 0.58 & 0 & 0.79 & 0.28 & 36 & 0.94 & 0.13 & 48 & 1.24 & 0.25 & 33 \\
\hline 0.58 & 50 & 0.26 & 0.58 & 22 & 0.40 & 0.27 & 42 & $(0.66$ & $0.11)^{e}$ & \\
\hline
\end{tabular}

\footnotetext{
Since the solubility of indigo in pyridine under the experimental conditions is about $0.14 \mathrm{mM}$ (cf. text), most of these solutions were saturated and contained excess solid indigo.

This solution was the same as the previously listed $0.11 \mathrm{mM}$ solution after standing for 3 months in a laboratory hood in a glass-stoppered flask.

${ }^{c}$ This solution was heated until all of the indigo dissolved; on cooling to $25^{\circ} \mathrm{C}$., the solution remained clear.

dPrepared by adding an excess of indigo to pyridine, centrifuging to remove the solid and diluting an aliquot of the supernatant liquid.

eMaximum on limiting current portion of wave.
}

in Fig. 1 (all currents are corrected to a $0.10 \mathrm{mM}$ indigo basis, assuming a linear variation of current with concentration). The second and third wave heights decrease to zero, while the first wave increases linearly to a limiting maximum at a ratio of 1.6 protons per indigo molecule; the total current remains constant at $0.58 \pm 0.04 \mu \mathrm{A}$., which corresponds to a diffusion current constant (I) of $3.72 \pm 0.26$.

The corresponding variation of the half-wave potential, $E_{1 / 2}$, with increasing [pyr $\mathrm{HNO}_{3}$ ]/[indigo] ratio for the $0.11 \mathrm{mM}$ indigo solution is shown in Fig. 2. There is a sigmoidal decrease in $\mathbf{E}_{1 /}$ at a ratio of 1.5 to 2 protons per indigo molecule, supporting the limiting current data at the D. M. E. 


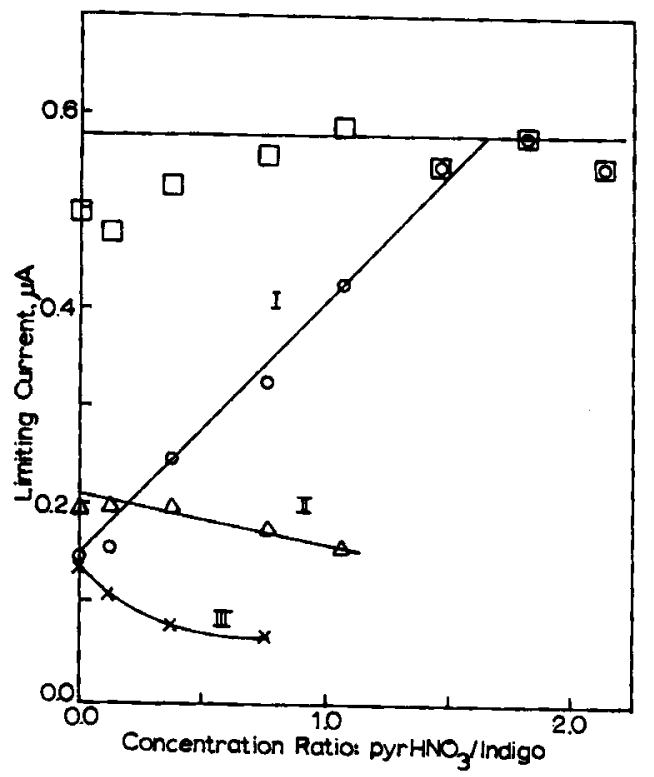

FIG. 1. Variation of the wave heights for the reduction of indigo $(0.11 \mathrm{mM})$ in pyridine $\left(0.1 \mathrm{M}\right.$ in $\left.\mathrm{LiClO}_{4}\right)$ with the ratio of available protons (added as pyridinium nitrate) to indigo. Roman numerals refer to the waves; rectangles to the sum of the waves.
Data for a $0.5 \mathrm{mM}$ indigo solution (saturated solution plus solid indigo) (Table I) show a single wave of constant height on acid addition with $E_{1 / 2}$ becoming more positive with increasing acid concentration; the wave height of $0.68 \pm$ $\pm 0.03 \mu \mathrm{A}$. corresponds to a concentration of $0.13 \mathrm{mM}$ on the basis of the total current for the $0.11 \mathrm{mM}$ solution.

\section{Tetraethylammonium Perchlo- rate Background}

Indigo solutions in $0.1 \mathrm{M}$ $\mathrm{Et}_{4} \mathrm{NClO}_{4}$ containing undissolved indigo show erratic polarographic behavior (Table I). Based on this behavior and that in $\mathrm{Et}_{4} \mathrm{NClO}_{4}$ solutions during exhaustive electrolysis, it was decided to concentrate on the use of solutions containing $0.1 \mathrm{M} \mathrm{LiClO}_{4}$ as background electrolyte.

\section{Cyclic Voltammetry of Indigo}

In order to establish that the reduction of indigo at the mercury pool electrode used in coulometry involves the consumption of two protons per indigo molecule, the effects of acid addition on the peak potentials, $E_{p}$, and peak currents, $i_{p}$, obtained on cyclic voltammetry of indigo in $0.1 \mathrm{M} \mathrm{LiClO}_{4}$ solution at the pool electrode were investigated. In order to obtain more readily interpretable results, a concentration of indigo below saturation was used, even though the exhaustive electrolyses were performed on saturated solutions exhibiting two rather than three waves.

Typical voltammograms are given in Fig. 3 ; the data are summarized in Table II. A plot of $\mathrm{E}_{\mathrm{p}}$ vs the [pyrHNO $\mathrm{H}_{3}$ ]/[indigol ratio for the first wave of a $0.11 \mathrm{mM}$ indigo solution is a sigmoidal curve with its mid-point at $-0.46 \mathrm{~V}$ and a ratio of 1.95 , indicating that two protons are being consumed for every indigo molecule reduced. 


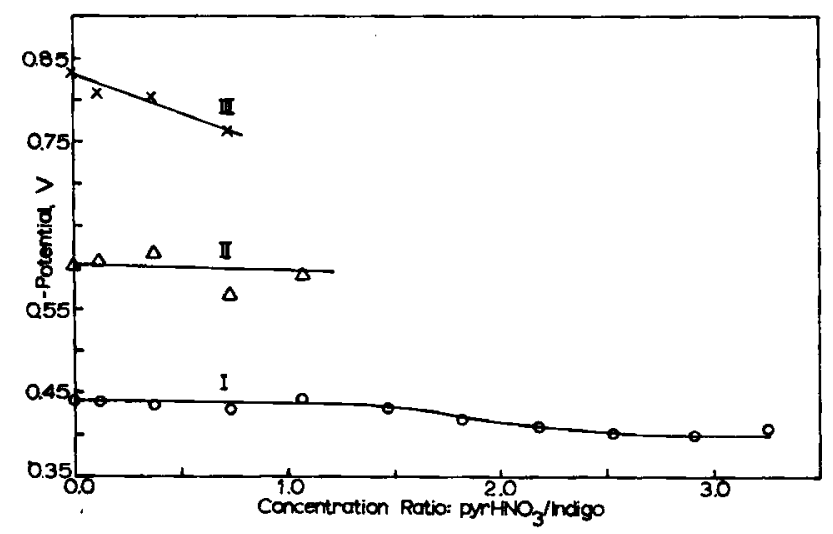

FIG. 2. Variation of the half-wave potentials for the reduction of indigo $(0.11 \mathrm{mM})$ in pyridine $\left(0.1 \mathrm{M}\right.$ in $\left.\mathrm{LiClO}_{4}\right)$ with the ratio of available protons (added as pyridinium nitrate) to indigo. Roman numerals refer to the waves.

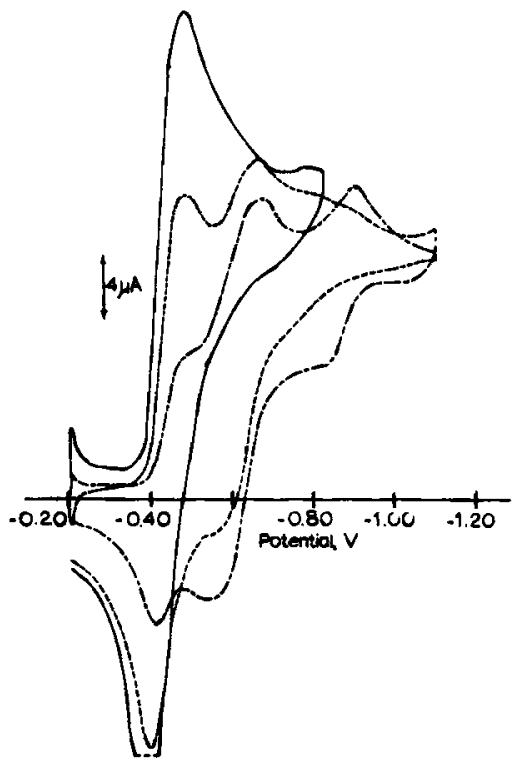

FIG. 3. Cyclic voltammograms for indigo in 0.1 $\mathrm{M} \mathrm{LiClO}_{4}$ solution at a mercury pool electrode. Scan rate: $3.33 \mathrm{mV} / \mathrm{sec}$. Pyridinium nitrate/ indigo ratio: broken line, 0.0 ; da shed line, 0.49 ; solid line, 1.07. Original indigo concentration $=0.14 \mathrm{mM}$ (cf. Table II). 
TABLE II. Cyclic voltammetric patrern of indigo in pyridine on proton addition ${ }^{2}$

\begin{tabular}{|c|c|c|c|c|c|c|c|c|c|c|}
\hline \multirow{4}{*}{$\frac{\text { Concn. }}{\text { Ratio }}$} & \multicolumn{6}{|c|}{ Cathodic Pattern } & \multicolumn{4}{|c|}{ Anodic Pattem } \\
\hline & \multicolumn{2}{|c|}{ Wave I } & \multicolumn{2}{|c|}{ Wave II } & \multicolumn{2}{|c|}{ Wave III } & \multicolumn{2}{|c|}{ Wave I } & \multicolumn{2}{|c|}{ Wave II } \\
\hline & $-E_{p}$ & $\mathrm{i}_{\mathrm{p}}$ & $-E_{p}$ & $i_{p}$ & $-E_{p}$ & $i_{p}$ & $-E_{p}$ & $i_{p}$ & $-E_{P}$ & $i_{p}$ \\
\hline & V & $\mu \mathrm{A}$ & V & $\mu \mathrm{A}$ & $\mathrm{V}$ & $\mu \mathrm{A}$ & $\mathrm{V}$ & $\mu \mathrm{A}$ & V & $\mu A$ \\
\hline 0.00 & 0.48 & 7.4 & 0.67 & 8.6 & 0.91 & 4.2 & 0.41 & 2.7 & 0.53 & 4.9 \\
\hline 0.49 & 0.48 & 16.8 & 0.66 & 3.8 & & & 0.39 & 12.5 & $0.64^{b}$ & 2.0 \\
\hline 1.07 & 0.48 & 28.0 & & & & & 0.38 & 20.6 & & \\
\hline 2.18 & 0.45 & 28.8 & 0.68 & 0.9 & & & 0.37 & 20.2 & & \\
\hline 2.53 & 0.44 & $20.3^{c}$ & & & & & & & & \\
\hline 2.91 & 0.43 & 21.6 & & & & & 0.36 & 14.0 & & \\
\hline 4.00 & 0.42 & 22.6 & & & & & 0.36 & 14.6 & & \\
\hline 5.09 & 0.42 & 24.9 & & & & & 0.35 & 16.0 & & \\
\hline 6.07 & 0.41 & 35.3 & & & & & 0.34 & 26.6 & & \\
\hline
\end{tabular}

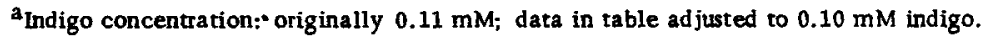

Background: $0.1 \mathrm{M} \mathrm{LiClO}_{4}$. Scan Rate: $3.33 \mathrm{mV} / \mathrm{sec}$. Protons added as pyridinium nitrate.

Mercury pool electrode.

${ }^{b}$ This is $\mathrm{E}_{\mathrm{p} / 2}$ since $\mathrm{E}_{\mathrm{p}}$ was too flat for precise measurement.

CThe area of the mercury pool was decreased for this and the following data points.

\section{Exhaustive Electrolysis of Indigo}

The results of exhaustive electrolysis and coulometry of indigo at controlled electrode potential are summarized in Table III.

In the absence of an added proton source, electrolysis on the limiting portion of the first wave indicates a one-electron (1e) transfer in both $\mathrm{LiClO}_{4}$ and $\mathrm{Et}_{4} \mathrm{NClO}_{4}$ solutions; electrolysis on the second wave indicates an overall $2 \mathrm{e}$ transfer in $\mathrm{LiClO}_{4}$. The latter value of $2 \mathrm{e}$ could be obtained only after oxygen was removed from the reference and counter electrode compartments as well as from the working electrode compartment.

Electrolysis at both wave I and II potentials in both background media produces unstable primary products, which are oxidizable and which decompose to secondary products capable of being reduced at the potential used for electrolysis on wave II, e.g., polarograms of the freshly reduced solutions show anodic waves, which decrease with time while cathodic waves appear in the region of indigo wave II; the effect is pronounced when the counter and reference compartments are not deaerated, indicating reaction of the anodic-wave producing material with oxygen diffusing from them into the working electrode compartment and a cyclic reduction of indigo. Such behavior effectively precludes the use of indigo reduction products produced in the absence of protons for the determination of oxygen.

\section{Effect of Protons}

Electrolysis of indigo in the absence of oxygen but in the presence of

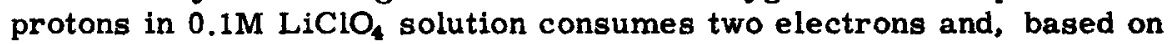
proton addition studies, two protons per indigo molecule, resulting in a 
stable primary product as indicated by consecutive polarograms on the reduced solution. Since a large excess of pyridinium nitrate improved the appearance of the polarograms, probably by aiding in the prevention of free radical side reactions, it was decided to use a $50 \mathrm{mM}$ proton concentration for the determination of oxygen via the indigo redox couple.

The failure to reach background current on the exhaustive electrolysis of indigo in $0.1 \mathrm{M} \mathrm{Et}_{4} \mathrm{NClO}_{4}(50 \mathrm{mM}$ in acid) was one factor precluding use of this medium for the oxygen determination.

TABLE II. Exhaustive coulometric electrolysis of indigo in pyridine

\begin{tabular}{cccll}
$\begin{array}{c}\text { Indigo } \\
\text { Taken } \\
\mathrm{mM}\end{array}$ & $\begin{array}{c}\text { HeyrNO } \\
\text { Concn. } \\
\mathrm{mM}\end{array}$ & $\begin{array}{c}\text { Appld. } \\
\text { Potl. } \\
\mathrm{V}\end{array}$ & $\mathrm{n}$ & Notes $^{\mathrm{b}}$ \\
\hline 0.2 & 0.0 & -1.20 & & $\mathrm{c}, \mathrm{d}, \mathrm{e}$ \\
2.0 & 0.0 & -0.70 & 0.90 & $\mathrm{e}, \mathrm{f}$ \\
2.0 & 0.0 & -1.20 & 2.06 & $\mathrm{e}, \mathrm{g}$ \\
0.50 & 1.0 & -0.70 & 1.89 & $\mathrm{e}, \mathrm{h}$ \\
0.50 & 1.0 & -0.56 & 2.20 & $\mathrm{e}, \mathrm{i}$ \\
0.50 & 10.0 & -0.40 & 2.15 & $\mathrm{e}$ \\
0.50 & 50.0 & -0.40 & 2.27 & $\mathrm{e}$ \\
& & & 1.93 & $\mathrm{j}$ \\
2.0 & & & 1.52 & $\mathrm{k}$ \\
0.50 & 0.0 & -0.90 & 1.07 & $\mathrm{l}$ \\
\hline
\end{tabular}

aconcentration is that which would exist if the indigo taken had dissolved.

bunless otherwise noted, all compartments were deaerated and electrolysis was continued to background current, which was used as a correction.

$c_{B a c k g r o u n d}$ current not reached after passage of coulombs equivalent to $12 \mathrm{e}$; air oxidation of reduced solution gave green precipitate.

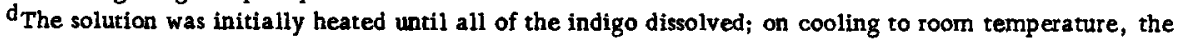
solution remained clear.

Background electrolyte: $0.1 \mathrm{M} \mathrm{LiClO}_{4}$.

f Only working compartment deaerated.

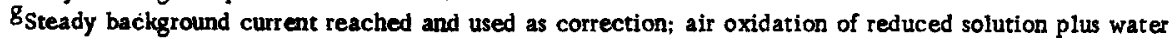
addition precipitated indigo, leaving a reddish solution.

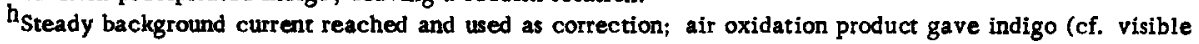
spectrum).

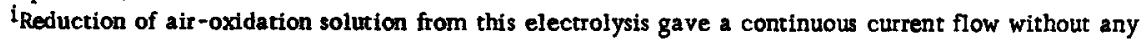
leveling off; air oxidation of the resulting solution produced a green solution and a dark precipitate. Evidently, indigo cannot be taken through a second redox cycle in the presence of a ratio of only 2 protons per indigo molecule.

$j$ Value of $n$ obtained on reduction of alr-oxidized solution from previous experiment, which had the indigo spectrum.

$k$ Value of $\mathbf{n}$ obtained on reduction of air-oxidized solution from experiment covered by footnote $f$.

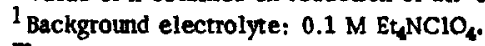

melectrolytic reduction of the air-oxidized solution from this electrolysis did not reach background current. 


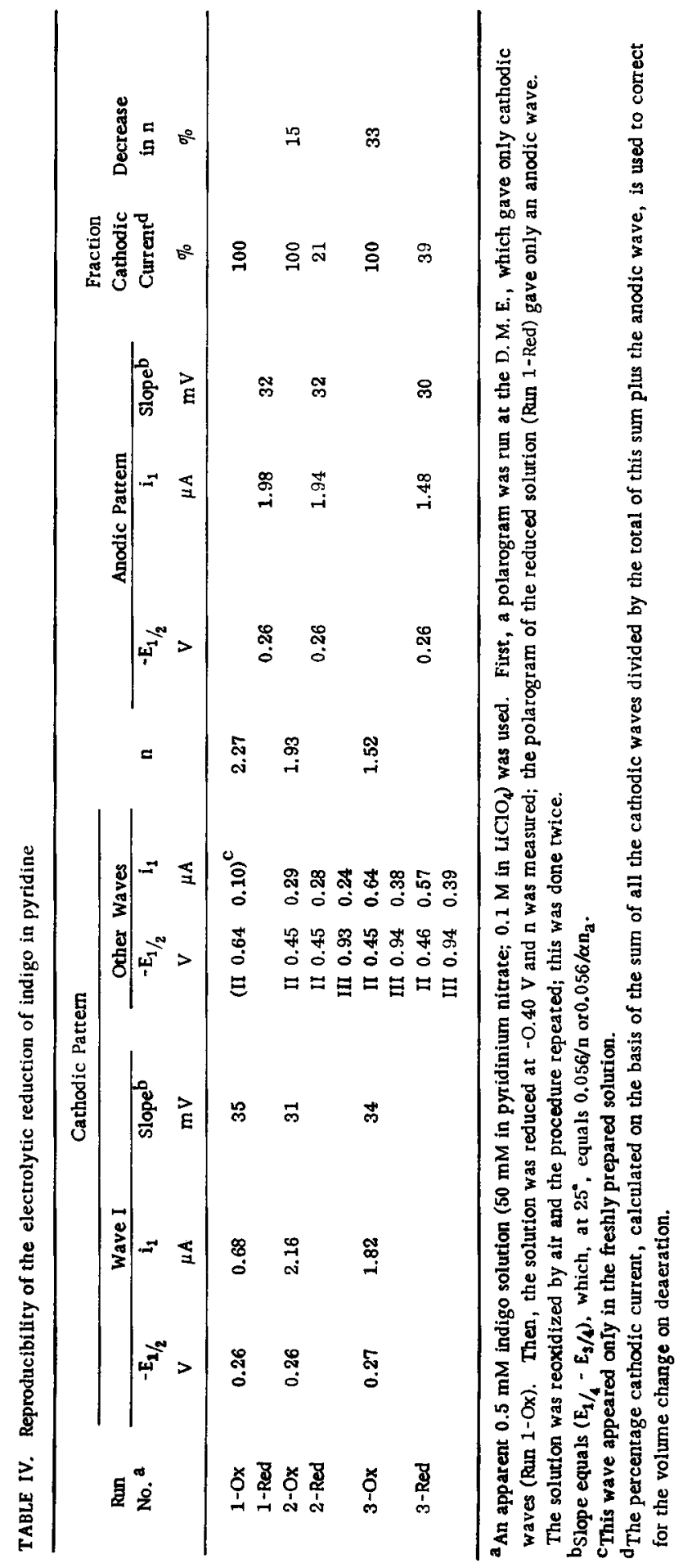




\section{Repeatibility of Polarographic Pattern:}

Table IV summarizes data for the repetitive reduction of indigo and air oxidation of the reduction product back to indigo, using the procedures described in the Experimental section.

TABLE V. Determination of dissolved oxygen concentration in pyridine by means of indigo redox couple

\begin{tabular}{ccccc} 
& Sample & \multicolumn{2}{c}{ Oxygen Content } \\
Sample & $\begin{array}{c}\text { Volume } \\
\mathrm{ml}\end{array}$ & $\begin{array}{c}\text { Found } \\
\text { Corrected }\end{array}$ \\
& & $\mathrm{mM}$ & $\mathrm{mM}$ \\
\hline
\end{tabular}

Air-Saturated Pyridine (0.1 $\mathrm{M} \mathrm{LiClO})$

$\begin{array}{llll}1 & 3.0 & 0.11 & 0.13 \\ 2 & 3.0 & 0.13 & 0.16 \\ 3 & 3.0 & 0.12 & 0.15\end{array}$

Air-Saturated Pyridine

\begin{tabular}{llll}
1 & 1.0 & 0.24 & 0.29 \\
2 & 1.0 & 0.26 & 0.32 \\
3 & 0.5 & 0.30 & 0.36 \\
4 & 0.25 & 0.38 & 0.46 \\
\hline
\end{tabular}

a Corrected on the basis of $18 \%$ side reaction as calculated from the Table IV data (cf. text).

The excellent agreement between $E_{1 / 2}$ and wave slope for the main anodic and cathodic waves indicates that a reversible $2 \mathrm{e}$ couple is involved and that indigo is indeed the product of the air oxidation of the material producing the anodic wave. The absorption spectrum (visible region) for a diluted solution of the air-oxidized product confirms that it is indigo.

The decrease in apparent faradaic $\mathrm{n}$ and the increase in cathodic current in the polarographic pattern for the reduced species, as successive electrolytic reduction and air oxidations are performed, of $16.5 \%$ and $19.6 \%$, respectively, support one another and indicate an average $18 \%$ loss of indigo on air oxidation of the product of the electrolytic reduction, which must necessarily be taken into consideration in the determination of dissolved oxygen.

Interestingly, the curves of current flow vs total quantity of electricity passed for the first and second reduction cycles (Fig. 4) indicate that the indigo formed on air oxidation has a higher solubility in the pyridine medium than the originally added indigo, i.e., whereas the rate of electrolys is for the second electrolysis is that expected for a homogenous solution, that for the original electrolysis is that expected for a solution whose concentration is kept nearly constant by the dissolution of solid reactant as the reaction proceeds with the rate becoming that for a homogeneous solution when all the solid has dissolved. This difference in solubility may result from solvation phenomena or other alteration in structure as subsequently discussed. 


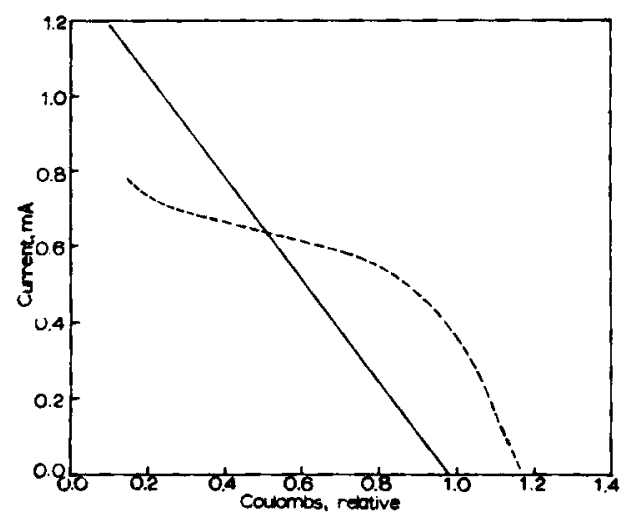

FIG. 4. Variation of current flow with total quantity of coulombs passed during electrolytic reduction of $5 \mathrm{mM}$ indigo in pyridine $\left(0.1 \mathrm{M} \mathrm{LiClO}_{4}: 50 \mathrm{mM}\right.$ pyridinium nitrate). Dashed line, first electrolysis; solid line, second electrolysis.

\section{Indirect Coulometric Determination of Oxygen}

Typical results for the determination of dissolved oxygen concentration (Table V) in air-saturated $0.1 \mathrm{M} \mathrm{LiClO}_{4}$ pyridine solutions by coulometric measurement of the indigo produced are in satisfactory agreement with a mean corrected value of $0.147 \mathrm{mM}$ and a standard deviation of $0.015 \mathrm{mM}$. The values for oxygen in pyridine indicate the much greater solubility of oxygen when the salt concentration is decreased and the decreased precision of the method when smaller sample volumes are used.

\section{Discussion}

Although the primary objective of the present study of the electrochemical reduction of indigo in pyridine solution was not to elucidate completely its polarographic behavior, some quantitative as well as qualitative conclusions may be drawn from the data obtained. In this connection, it should be emphasized that the polarographic characteristics of indigo are dependent on its concentration, i.e., saturated or not, in freshly prepared solution; heating or aging of the solution produces changes, which may be linked to solvation effects.

\section{Faradaic $n$ Values}

In solutions which contain indigo at concentrations below saturation in the absence of a proton source, there is some indication that, based on comparison of the calculated diffusion current constant (I) values to the 
I value for a known $2 e$ reduction, the sum of the currents for waves I and II represents a le transfer. For fresh $0.11 \mathrm{mM}$, aged $0.11 \mathrm{mM}$, and heated $0.20 \mathrm{mM}$ indigo solutions (Table I), the calculated I values are $1.81,1.81$, and 1.83 , respectively. The I value for the established $2 e$ reduction of benzophenone (a molecule whose size is comparable to that of indigo) in pyridine is $4.0[10]$. This would indicate a $1 \mathrm{e}$ reduction for the indigo.

For solutions containing indigo at concentrations below saturation in the presence of protons, the calculated I value is 3.72 , comparison of which to the I value for benzophenone indicates a polarographic $2 \mathrm{e}$ reduction.

In fresh solutions (proton absent) containing solid indigo, the first and second waves appear on the basis of coulometry (Table III) to involve le transfers. In the presence of a two-fold or greater excess of protons compared to indigo, a 2 e reduction occurs.

\section{Redox Mechanisms}

The electrolytic reduction of indigo in the presence of excess available protons involves the consumption of two electrons and two protons per indigo molecule in a macroscopically reversible redox reaction. Polarographic wave slopes approach those expected for a reversible $2 \mathrm{e}$ transfer. The reduction product, based on analogy with the aqueous chemical reduction, is indigo white or leucoindigo. The half-reaction for the couple in pyridine is accordingly of the form<smiles>O=C1C(=C2NC(=O)c3ccccc32)Nc2ccccc21</smiles><smiles>Oc1c(-c2[nH]c3ccc(C=C=[PH2+])cc3c2O)[nH]c2ccccc12</smiles>

where the protons are furnished by pyridinium ions from the probably largely dissociated pyridinium nitrate $[11,12]$.

Air oxidation of the reduced form produces indigo with some loss, apparently due to side reaction. In any case, the effect of side reactions during oxidation and reduction may be kept reproducibly constant at $18 \%$ indigo loss per cycle by adding an excess of acid (actually, available proton) to the solution containing the solid phase. The indigo formed on air oxidation, based on visual observation and the relation of current flow to quantity of electricity passed on electrolysis, forms a true solution, which may be due to the indigo thus prepared being more highly solvated than solid indigo placed in contact with pyridine (cf. subsequent discussion).

The apparent initial le reduction of indigo observed in the absence of available protons (sum of waves I and II for unsaturated solution or wave I for saturated solutions) is generally characteristic of the electrochemical reduction of carbon-carbon and carbon-oxygen double bonds, and aromatic $r$ ing systems in aprotic media, where the initial le reduction produces a free radical anion which may survive for an appreciable time, may dimerize or may rearrange or decompose; there is generally a second 1 e reduction 
at more negative potential [13]. The addition of available protons usually causes the first wave to grow at the expense of the second wave with the sum of the waves remaining constant.

The splitting of the initial le process for indigo into two waves and the resulting three-wave pattern in unsaturated solution, and the increased solubility of indigo producted in solution by the oxidation of electrochemically reduced indigo are likely to be due to the effect of available protons, the resonance forms of indigo and leucoindigo, and the interaction of the solvent pyridine with hydrogen bound to oxygen or nitrogen in the indigo and leucoindigo.

In indigo, the two indoxyl moieties are connected by a double bond, which is conjugated with both carbonyl groups; in addition, there are possibilities for hydrogen bonding, which results in internal chelation and which may well favor the polar canonical structure to the extent where the compound is definitely polar:

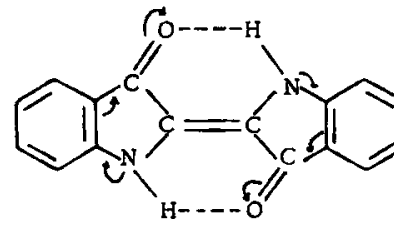

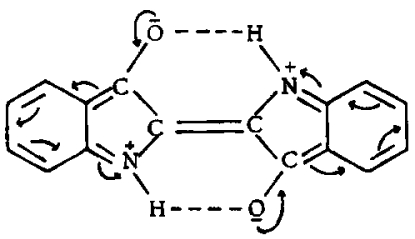

The fact that indigo must then have the character of an internal salt, accounts for indigo being normally dark blue as contrasted to the yellow indoxyl and the colorless leucoindigo (salt formation is known to deepen the color). However, indigo is dark blue only in polar solvents where the solvent dipoles aid in favoring the polar canonical structures; in nonpolar solvents, the indigo color is the less deep red [14]. Solutions of indigo in pyridine are dark blue; leucoindigo solutions are clear and colorless.

Resonance forms can be similarly written for the leucoindigo, e.g., with the hydrogens indicated in equation 1 as being attached to oxygen being attached to the carbon-carbon bond between the two dimerized indoxyl radicals. A basic solvent such as pyridine would favor the form written in Eq. (I) since it would be expected to react with the enolic (quasi phenolic) hydrogen and the hydrogen on the nitrogen in the heterocyclic ring of the leucoindigo; references 11 and 12 discuss the relative enhancement in pyridine of the acidity of phenols and purines compared to carboxylic acids as a result of the formation of the Lewis acid-base adduct and its dissociation equilibria:

$$
\mathrm{HA}+\mathrm{pyr} \rightleftharpoons \text { pyr---H--A, } \operatorname{pyrH}^{+} \mathrm{A}^{-}=\mathrm{pyrH}^{+}+\mathrm{A}
$$

where pyr---H-- $A$, the hydrogen bonded adduct, and $\operatorname{pyrH}^{+} \mathbf{A}^{-}$, the completely undissociated ion pair, represent the extremes of the associated adduct. Furthermore, pyridine will compete with the carbonyl oxygen in forming hydrogen bonds with the hydrogen on the nitrogen in indigo itself (cf.Eq. (II)). 
Thus, the increased solubility of indigo produced on oxidation of leucoindigo is likely to be due to the polyadduct of the latter with pyridine, which produces a solvated indigo species, whereas the dissolution of solid indigo, which is strongly internally hydrogen-bonded in the solid state, involves overcoming the high energy barrier of breaking the internal chelation by the formation of bonds with pyridine.

One possible explanation for the three-wave pattern in unsaturated solution of indigo with the two-wave pattern in saturated solution containing excess solid in the absence of a proton source is the following.

In unsaturated solution (no protons), wave $I$ at $-0.45 \mathrm{~V}$ represents the initial $1 \mathrm{e}$ reduction of dissolved indigo to produce a free radical anion and wave II at $-0.60 \mathrm{~V}$ represents a similar process due to indigo adsorbed on the electrode. (Since adsorbed molecules are in a lower free energy state than those in solution, they are more difficultly reduced.) Wave III at $-0.85 \mathrm{~V}$ represents the further $1 \mathrm{e}$ reduction of indigo, which is less than the sum of waves I plus II due to the instability of the initially produced free radical anion.

The postulated $1 \mathrm{e}$ reductions for waves I and II to form free radical anions, as well as the addition of a second electron in wave II, are supported in part by the cyclic voltammetric results at the mercury pool, e.g., both waves I and II have associated anodic waves at zero and 0.49 ratios of [pyrHNO $\mathrm{H}_{3}$ ]/[indigo], whereas wave III does not (Table Il, Fig. 3 ). Russell and Kaupp [15] have demonstrated by electron spin resonance spectroscopy the reduction (in methanol by chemical agents) of indigo to indigo radical anion and thus to leucoindigo. It is possible that waves I and/or II contain a small amount of $2 e$ reduction of the indigo.

In saturated solution in the presence of excess solid indigo, wave I at $-0.60 \mathrm{~V}$ represents the initial le reduction of adsorbed indigo and wave II at $-0.89 \mathrm{~V}$ is due to the further reduction with the relative magnitudes of the waves complicated by dissolution and other phenomena connected with the use of saturated solutions.

Addition of available protons causes wave $I$ at $-0.45 \mathrm{~V}$ for the unsaturated solutions to grow at the expense of wave III, since the free radical anion initially produced is immediately protonated and, because a neutralized free radical is generally more easily reduced than its parent compound [13], the neutral free radical is further reduced as soon as it is formed. Wave I also grows at the expense of wave II because of the likelihood that indigo in the presence of protons near the solution-electrode interface is protonated and consequently less adsorbed in the potential region of waves I and II, which is near that of the electrocapillary maximum.

The presence of protons would similarly account for the merging of the two waves in saturated solution to one wave at more positive potential.

Alternate explanations for the indigo wave pattern are possible. Thus, examination of Figs. 1 and 2 for the variation of limiting current and $\mathbf{E}_{1 / 2}$ with proton availability for an unsaturated indigo solution, which supports the previously postulated mechanism, also permits the hypothesis that wave I represents the initial $1 \mathrm{e}$ reduction and wave III 
the second 1e reduction of one form of indigo and wave II represents the $2 e$ reduction of another form of indigo with increasing proton availability favoring the formation of the process producing wave $I$ as well as the absorption of the wave III process into wave I. However, the reversible behavior of wave II on cyclic voltammetry would indicate that a $2 \mathrm{e}$ process is improbable, because the dianion formed would be expected to be extremely short lived.

Although the accuracy of the coulometric method for dissolved oxygen based on the reversible indigo redox couple has not been firmly established, the precision of the method is satisfactory.

\section{ACKNOWLEDGMENTS}

The authors thank the National Science Foundation and the Petroleum Research Fund of the American Chemical Society for helping to support the work described.

\section{REFERENCES}

1. W.M.CLARK, B.COHEN, et al., Studies on Oxidation-Reduction I-X, Hygienic Laboratory Bulletin No. 151, U.S. Public Heaith Service, Washington, 1928.

2. A.K.GUPTA, J. Chem. Soc., $3473,3479(1952)$

3. O.H.MǗller, A n n. N. Y. A cad. Sci., 40, 91 (1940)

4. O. H. MÜLleR, J. Biol. Chem., 145, 425 (1942)

5. I. M.KOLTHOFE and J.I LINGANE, Pola tography, 2nd ed., Vol. 1, p. 261, Interscience Publishers, New York, (1952)

6. I. A. KORSHUNOV, L. N. SAZANOVA, M. K. SHCHENNIKOVA and O.P. MALKOVA, Z a vodsk a y L a b., 15, 1287 (1949); Chem. A bstr., 44, 3846 (1950)

7. D. A. HALL and P.J. ELVING, Anal, Chim. Acta, 39, 141 (1967)

8. A.CISAK and P.J.ELVING, J. Electrochem. Soc., 110, 160 (1963)

9. D. A.HALL, M. SAKUMA and P.J. ELVING, Electrochim. Acta, 10, 309 (1965)

10. R.F.MICHIELLI and P.J.ELVING, J. Amer. Chem. Soc., 90, 1989 (1968)

11. K. TSUII and P. J. ELVING, A na I. Che m., 41, 286 (1969)

12. K. TSUJI and P.J.ELVING, A na l. Chem., 41, 1571 (1969)

13. M.E.PEOVER in Electroanalytical Chemistry, A.J.BARD, ed., Vol. 2, pp. 1-51, Marcel Dekker, New York (1957)

14. A.GERO, Textbook of Organic Chemistry, John Wiley and Sons, New York (1963)

15. G. A. RUSSEll and G. KAUPP, J. A mer. Chem. Soc., 91, 3851 (1969) 